\title{
Dedifferentiated Chondrosarcoma Demonstrating Osteosarcomatous Differentiation
}

\author{
Baljinder S. Dhinsa ${ }^{a}$ Mariagrazia DeLisa ${ }^{b}$ Rob Pollock ${ }^{c} \quad$ Adrienne M. Flanagan $^{c}$ \\ Jeremy Whelan ${ }^{\mathrm{d}}$ Jonathan Gregory \\ ${ }^{a}$ William Harvey Hospital, Ashford, UK; \\ b Università Politecnica delle Marche, Azienda Ospedaliero-Universitaria Ospedali Riuniti Umberto I, Ancona, Italy; \\ ${ }^{\mathrm{c}}$ Royal National Orthopaedic Hospital NHS Trust, Stanmore, UK; \\ ${ }^{\mathrm{d}}$ The London Sarcoma Service, University College Hospital, London, UK; \\ ${ }^{\mathrm{e}}$ The Royal Orthopaedic Hospital NHS Trust, Birmingham, UK
}

\section{Keywords}

Bone neoplasm · Chemotherapy · Adjuvant ·

Chondrosarcoma - Osteosarcoma .

Retrospective studies · Necrosis · Anaplasia

\section{Summary}

Background: Dedifferentiated chondrosarcoma (DDC) accounts for a small proportion of chondrosarcomas. They demonstrate aggressive behaviour with a high rate of local recurrence and systemic progression resulting in poor long-term survival rates. Due to its relatively low incidence, previous studies have grouped different histiotypes together to achieve adequate study numbers for analysis. Methods: This retrospective study examines the clinical course and the role of chemotherapy in the subgroup of patients with DDC where osteosarcoma is the predominant dedifferentiated component. Between 2000-2010, 21 patients were identified. Results: The mean age at presentation was 64 years (range 35-80 years). 12 patients were considered unfit for chemotherapy, whilst 2 patients declined chemotherapy. 5 patients received neoadjuvant chemotherapy, with less than $90 \%$ necrosis demonstrated in all these cases. 3 patients received post-operative chemotherapy. The median survival for the entire group was 9.5 months. In the 7 patients who received chemotherapy, the median survival was 17 months, and those who had chemotherapy had a greater median time to local recurrence. Conclusion: This study demonstrates that cytotoxic chemotherapy may be offered to appropriately selected patients.

() 2018 S. Karger GmbH, Freiburg

\section{Introduction}

Dedifferentiated chondrosarcoma (DDC) accounts for approxi- mately $10 \%$ of chondrosarcomas [1]. Patients typically present with progressive pain or pathological fracture and frequently have ad- vanced disease. Unlike most conventional chondrosarcomas, DDC demonstrates very aggressive behaviour with a high rate of local recurrence (LR) and systemic progression resulting in a median survival of 6 months [2,3].

DDC was described by Dahlin and Beabout [1] in 1971 and is characterised by its bimorphic nature with distinct regions of low- grade chondrosarcoma bordering high-grade, noncartilaginous sarcoma [4]. The dedifferentiated component may have the ap- pearance of a high-grade undifferentiated sarcoma, osteosarcoma or, less commonly, angiosarcoma [5]. Given the rarity of DDC, studies usually group the different high-grade histiotypes together to achieve adequate numbers for analysis. This results in study populations that are heterogeneous and, consequently, conclusions are rarely robust (table 1). No previous study has solely addressed DDC with osteosarcomatous differentiation.

Clinical management typically involves surgery, with limb sal- vage or amputation of the affected limb. High LR rates have been reported after excision, with no difference in outcome demon- strated between limb salvage and amputation [6]. The role of chemotherapy in addition to surgery is uncertain [7], with incon- clusive results from several small series.

The role of chemotherapy is relevant when the high-grade spin- dle cell component may be chemosensitive $[3,7,8]$. As chemother- apy accounts for a significant improvement in survival in patients with osteosarcoma, it was suggested that it could have a role in the management of DDC where the dedifferentiated component dem- onstrates osteosarcomatousfeatures [7,9]. Therehavebeenreports 
Table 1. Studies investigating DDC

\begin{tabular}{|c|c|c|c|c|}
\hline Authors & $\begin{array}{l}\text { No. of } \\
\text { pts } \\
\text { (DDC) }\end{array}$ & $\begin{array}{l}\text { No. of DDCs with } \\
\text { osteosarcomato } \\
\text { us } \\
\text { dedifferentiation }\end{array}$ & $\begin{array}{l}\text { No. of pts } \\
\text { treated with } \\
\text { chemotherap } \\
\text { y }\end{array}$ & $\begin{array}{l}\text { Median } \\
\text { survival } \\
\text { time, } \\
\text { months }\end{array}$ \\
\hline Dhalin and Beabout [1] & 33 & 11 & $\mathrm{~N} / \mathrm{A}$ & N/A \\
\hline McFarland et al. [2] & 4 & 2 & 0 & 12 \\
\hline Campanacci et al. [3] & 25 & 3 & $\mathrm{~N} / \mathrm{A}$ & N/A \\
\hline $\begin{array}{l}\text { McCarthy and } \\
\text { Dorfman [4] }\end{array}$ & 18 & 3 & 0 & 6 \\
\hline Johnson et al. [5] & 26 & 2 & 12 & 6 \\
\hline Frassica et al. [6] & 78 & 42 & 10 & 10.5 \\
\hline Capanna et al. [7] & 46 & 18 & 30 & 10 \\
\hline Mercuri et al. [8] & 74 & 23 & 9 & 12 \\
\hline Mitchell et al. [9] & 22 & 6 & 9 & 9 \\
\hline Dickey et al. [10] & 42 & $\mathrm{~N} / \mathrm{A}$ & 22 & 7.5 \\
\hline Bruns et al. [11] & 13 & 3 & 5 & 9.7 \\
\hline Staals et al. [12] & 123 & 92 & 25 & 13 \\
\hline Staals et al. [13] & 18 & 9 & 7 & 14 \\
\hline Grimer et al. [14] & 337 & 104 & 81 & 16 \\
\hline \multicolumn{4}{|c|}{ 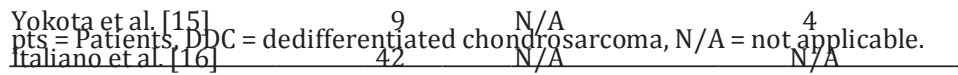 } & $\begin{array}{l}10 \\
\mathrm{~N} / \mathrm{A}\end{array}$ \\
\hline Kawaguchi et al. [17] & 41 & $\mathrm{~N} / \mathrm{A}$ & 25 & 18 \\
\hline
\end{tabular}

of cases demonstrating good histological response (considered more than $90 \%$ necrosis) $[6,10,11]$, and improvement in outcome with adjuvant chemotherapy [6] in DDC. However, these studies have omitted any specific analysis of those with osteosarcomatous differentiation.

A combination regimen based on doxorubicin and cisplatin is recommended by the National Comprehensive Cancer Network (NCCN) guidelines [12, 13]. Ifosfamide [14] or methotrexate [10] incorporated into the standard regimen has been reported in a small number of patients with DDC [11]. Despite aggressive ther- apy, the reported 2-year survival rate remains less than $20 \%$ [10].

This retrospective study specifically examines the characteristics and outcomes in the subgroup of patients with DDC where osteosar- coma is the predominant dedifferentiated component. In the context of a life-limiting aggressive disease, the intention was to identify fac- tors that may affect outcome and to assess the role of chemotherapy and if the toxicities associated with it were acceptable.

\section{Patients and Methods}

Between 2000 and 2010, 73 patients had a histological diagnosis of DDC at a single institution. All pathological specimens were re-reviewed. The histological criteria required for inclusion in the study were those outlined in the World Health Organisation (WHO) classification of tumours of soft tissue and bone [4]: a combination of well-differentiated chondrosarcoma and juxtaposed zones of high-grade non-cartilaginous sarcoma; cases in which the latter showed os- teosarcomatous differentiation were specifically sought. Of these patients, 21 (29\%) had evidence of osteosarcomatous differentiation. The portion of the tu- mour that demonstrated osteoblastic differentiation, whether focal of extensive, was also noted. The differentiated cartilaginous component was graded accord- ing to established criteria [4].

A retrospective review of the patients was performed using departmental records and clinical notes. Data collection included demographics, pathological features, surgical and oncological management, and outcome. Survival differences according to clinical and pathological parameters (age, sites, amount of osteosarcomatous differentiation and vascular invasion presence of fracture at diagnosis) and to treatment (type of surgery and surgery alone \pm chemother-apy) were evaluated by log-rank test due to the small number of patients.

\section{Results}

The patients' characteristics are summarized in table 2 . The mean age at presentation was 64 (range 35-80) years, with a sig- nificant male preponderance $(16$ male, 5 female patients). Appen- dicular bones were involved in $76 \%$ of the cases, with the femur being the most commonly affected bone. In 1 patient, DDC oc- curred on a background of Ollier's disease. 8 of the patients pre- sented with a pathological fracture (38\%), with all other patients presenting with pain and swelling in the affected areas. Radiologi- cally, all tumours showed a significant extraosseous component, with osteolytic lesions seen in $73 \%$, cortical perforation in $62 \%$ and bone expansion in 34\%. All patients were treated with surgery (limb-sparing resection 14, amputation 7).

On review of the histology, the cartilaginous component was

solely low grade in 13 cases: grade I in 9 cases ( 2 of which arose from a benign enchondroma) and grade II in 4 cases. 8 cases (38\%) included a grade III (high-grade) cartilaginous component. The relative proportion of osteosarcomatous component varied, being extensive in $57 \%$ of the cases and focal in the remainder. Coexist- ent high-grade undifferentiated sarcoma was present in $52 \%$ of the cases. Vascular invasion was identified in 7 cases. There was no difference in tumour characteristics between patients who had chem- otherapy and those who did not receive chemotherapy.

Twelve patients were considered to have insufficient perfor-mance status to be considered for systemic cytotoxic treatment. 2 
Table 2. Patient characteristics and tumour findings

\begin{tabular}{|c|c|}
\hline Characteristics & $\begin{array}{l}\text { Total number of } \\
\text { patients, n (\%) }\end{array}$ \\
\hline \multicolumn{2}{|l|}{ Age } \\
\hline$<65$ years & $7(33)$ \\
\hline$\geq 65$ years & $14(67)$ \\
\hline \multicolumn{2}{|l|}{ Sex } \\
\hline Male & $16(76)$ \\
\hline Female & $5(24)$ \\
\hline \multicolumn{2}{|l|}{ Site } \\
\hline \multicolumn{2}{|l|}{ Appendicular } \\
\hline Femur & $11(52)$ \\
\hline Tibia & $3(14)$ \\
\hline Humerus & $2(10)$ \\
\hline \multicolumn{2}{|l|}{ Central } \\
\hline Ilium & $4(19)$ \\
\hline Rib & $1(5)$ \\
\hline \multicolumn{2}{|l|}{ Pre-operative biopsy } \\
\hline Yes & $13(62)$ \\
\hline No & $8(38)$ \\
\hline \multicolumn{2}{|l|}{ Grade of chondral component } \\
\hline G1 (low grade) & $9(43)$ \\
\hline G2 & $4(19)$ \\
\hline G3 (high grade) & $8(38)$ \\
\hline \multicolumn{2}{|l|}{ Osteosarcoma differentiation } \\
\hline Focal & $9(43)$ \\
\hline Extensive & $12(57)$ \\
\hline \multicolumn{2}{|l|}{ Type of osteosarcoma differentiation } \\
\hline Osteoblastic & $8(38)$ \\
\hline Osteoblastic and fibroblastic & $2(10)$ \\
\hline Spindle cell sarcoma & $11(52)$ \\
\hline \multicolumn{2}{|l|}{ Vascular invasion } \\
\hline Present & $7(33)$ \\
\hline Absent & $14(67)$ \\
\hline \multicolumn{2}{|l|}{ Stage at diagnosis } \\
\hline M0 & $17(81)$ \\
\hline M1 & $4(19)$ \\
\hline \multicolumn{2}{|l|}{ Clinical onset } \\
\hline Pathological fracture & $8(38)$ \\
\hline No fracture & $13(62)$ \\
\hline \multicolumn{2}{|l|}{ Surgical treatment } \\
\hline Amputation & $15(71)$ \\
\hline Limb-preserving surgery & $6(29)$ \\
\hline \multicolumn{2}{|l|}{ Chemotherapy } \\
\hline Combined neoadjuvantand adjuvant & $1(5)$ \\
\hline Neoadjuvant plus surgery & $4(19)$ \\
\hline Adjuvant plus surgery & $3(14)$ \\
\hline No chemotherapy & $14(67)$ \\
\hline
\end{tabular}

patients declined chemotherapy. 5 patients received neoadjuvant chemotherapy with doxorubicin $\left(75 \mathrm{mg} / \mathrm{m}^{2}\right)$ and cisplatin $\left(100 \mathrm{mg} / \mathrm{m}^{2}\right) .3$ patients terminated treatment after 3 cycles: 2 due to lack of radiological evidence of a reduction in disease volume and 1 due to progressive disease. After resection, the assessment of path- ological response demonstrated less than $90 \%$ chemotherapy-in- duced necrosis in all 5 cases.

Three patients received post-operative chemotherapy, one of which had received pre-operative chemotherapy. This patient re- ceived 3 cycles of doxorubicin/cisplatin chemotherapy preopera- tively, resulting in progressive disease, and ifosfamide $\left(9 \mathrm{~g} / \mathrm{m}^{2}\right)$ and etoposide $\left(360 \mathrm{mg} / \mathrm{m}^{2}\right)$ post-operatively. Postoperative radio- therapy to the primary resection site was delivered in addition to chemotherapy in 2 cases. Although negative resection margins were obtained in these cases, radiotherapy was given to improve local control due to the large initial tumour size (greater than $10 \mathrm{~cm}$ ).

LR was seen in 9 patients, with 7 of these patients previously having limb-sparing surgery. 2 of the patients with LR had received chemotherapy. The median time to recurrence for the 9 patients was 5 months (range 2-19 months); however, for the 2 patients who had chemotherapy, the median time to LR was 13 months (range 6-19 months) compared to 2.5 months (range 2-6 months) for the 7 patients who did not have systemic therapy.

The median survival from diagnosis was 9.5 months (range 2-95 months), whilst in the 7 patients who received chemotherapy in addition to surgery the median survival from diagnosis was 17 months (range 8-58 months). Factors associated with a detrimen- tal effect on outcome were age over 65 years $(p=0.016)$, the pres- ence of vascular invasion in the specimen $(\mathrm{p}=0.012)$ and limb-preserving surgery ( $p$ $=0.049$ ). No differences were found related to the amount of osteosarcomatous differentiation, the presence of frac $<$ ture at diagnosis and the site of the primary.

Chemotherapy-related toxicities, classified according to the $\mathrm{Na}$ - tional Cancer Institute Common Terminology Criteria for Adverse Events (NCI-CTCAE v4.03) are shown in table 3. All toxicities were temporary and resolved with appropriate management. Gran- ulocyte colony-stimulating factors (GCSFs) were administered as prophylaxis with each cycle of chemotherapy. All patients experi- enced haematological toxicity: grade I-II anaemia in 2 patients and grade I thrombocytopenia in 1 patient. Febrile neutropenia (seen in $50 \%$ of patients) was managed with intravenous and oral antibi- otics. 3 patients developed renal dysfunction requiring switching to carboplatin. No evidence of chemotherapyrelated cardiotoxicity or peripheral neuropathy requiring dose reduction or interruption of treatment was reported.

\section{Discussion}

This study is the first to focus on the subgroup of patients with osteosarcomatous differentiation in DDC. This represents approxi- mately one-third of the cases of DDC. Half of the patients were not eligible for systemic therapy due to advanced stage of disease or co-morbidities. Only just over half of the potentially eligible pa- tients were treated with chemotherapy. These patients had a longer median survival (median of 17 months) compared to those patients who did not receive chemotherapy (median survival of 6 months). Chemotherapy was associated with side effects but these were all manageable and reversible. There was no difference in tumour characteristics or demographics between those who had chemo- therapy and those who did not.

The demographics of the patients in our study were consistent

with that reported for a large study of DDC with different histio- 
Table 3. Chemotherapy-related toxicities, classified according to the NCI-CTCAE v4.03

\begin{tabular}{|c|c|c|c|c|c|c|c|}
\hline Patient & Haematological toxicity & $\begin{array}{l}\text { Febrile } \\
\text { neutropeni } \\
\text { a }\end{array}$ & Renal toxicity & $\begin{array}{l}\text { Cardiac } \\
\text { toxicity }\end{array}$ & Neurotoxicity & $\begin{array}{l}\text { Gastrointestin } \\
\text { al toxicity }\end{array}$ & Others \\
\hline 1 & leucopenia G4 & yes & GFR reduced & no & no & diarrhoea G1 & no \\
\hline 2 & leucopenia G3, anemia G2 & no & GFR reduced & no & no & diarrhoea G1 & no \\
\hline 3 & leucopenia G4 & yes & GFR reduced & no & no & nausea/vomiting G2 & no \\
\hline 4 & leucopenia G3, anemia G1 & no & no & no & no & no & no \\
\hline 5 & leucopenia G4 & yes & no & no & no & no & no \\
\hline 6 & \multicolumn{7}{|c|}{ had chemotherapy in another centre in Ireland } \\
\hline 7 & $\begin{array}{l}\text { leucopenia G2, } \\
\text { thrombocytopenia } \\
\text { G1 }\end{array}$ & no & no & no & no & nausea/vomiting G1 & no \\
\hline
\end{tabular}

NCI-CTCAE = National Cancer Institute Common Terminology Criteria for Adverse Events, GFR = glomerular filtration rate .

types $[3,6,7,10]$. The overall median survival in our series of os- teosarcomatous DDC was 9.5 months (range 2-95 months), which is comparable to previous studies looking at all types of DDC. These studies reported median survival times ranging from 7.5 to 10 months $[6,8,11]$.

Staals et al. [12] reported on 123 cases, 92 of which showed fea- tures of osteosarcoma with an average follow up of 33 months. This study reported an overall superior median survival time of 13 months; with those having surgery alone having a median survival of 18 months, and a median survival of 23 months for those having both surgery and chemotherapy. The authors found no significant difference in survival when comparing those who had surgery and chemotherapy with those who had surgery alone. However, in this series, not only was there a heterogeneous sample but a variety of chemotherapy regimens were utilised and cases were collected over a large time period (1969-2003). Diagnostic and sampling tech- niques had changed within this period, which would affect the con- sistency of analysis. The LR rate was not reported in this study.

The LR rate in our series of osteosarcomatous DDC was high, with LR occurring in 9 cases after a median time of 5 months. 7 patients had been treated with limb-sparing surgery and 2 had re- ceived chemotherapy. This rate of failure of local control is in keeping with that reported in the literature in studies of DDC. In the series reported by Mitchell et al. [9] LR occurred in 9 out of 18 cases, 4 of which had wide margins of excision and 5 had intra-le- sional removal. Whilst Yokota el al. [15] had 2 cases of recurrence out of 8 cases, both had undergone amputation. It must be remem- bered that these studies had samples with heterogeneous dedifferentiated histiotypes. The median time to LR increased with the use of cytotoxic chemotherapy (13 vs. 2.5 months).

The role of chemotherapy has been reported in several studies

$[2,6,8,14]$. However, the validity of these studies is affected by the heterogeneous nature of the group of DDC analysed, as well as the variety of chemotherapy regimens utilised.

In contrast, Mercuri et al. [8] concluded that there was no ben- efit found from the use of adjuvant therapy, and Dickey et al. [10] found that the tumour response to pre-operative chemotherapy was poor. Our results support this conclusion, with less than $90 \%$ necrosis in all cases treated with neoadjuvant cytotoxic chemo- therapy. Mitchell et al. [9] demonstrated more than $90 \%$ necrosis in only 1 out 5 DDC cases treated with neo-adjuvant chemotherapy.

In our study, we only looked at osteosarcomatous DDC and all but 1 of the patients had the same chemotherapy regimen. How- ever, selection bias cannot be ruled out as a reason for the differ- ences reported, especially as chemotherapy was only considered for those with a satisfactory performance status, and these patients tended to be younger and healthier. In $52 \%$ of our cases a coexist- ent high-grade undifferentiated sarcoma was present, and one may argue that this should form part of the inclusion criteria in the fu- ture, as it is reasonable to presume that chemotherapy may be ben- eficial in these cases.

The poor prognosis and advanced stage of disease at diagnosis for many patients contribute to making the management of DDC challenging. It is against this background that the role of limb sal- vage surgery and chemotherapy are discussed. Questions prompted include: Is the poor prognosis in part due to the high rate of failure of local control? If this were the case, it could be argued that ampu- tation should be more widely used. However, the competing argu- ment would be that, in a tumour with poor prognosis, greater ef- forts should be made towards limb preservation. In this context, the suggestion from our data that duration of local control is in- creased by chemotherapy proposes a role for chemotherapy above that of improving overall survival. Chemotherapy may support local control in limb preservation surgery. The small numbers clearly prevent firm conclusions being drawn, but further work assessing the role of chemotherapy in the local control of this tumour would seem justified.

The primary aim of this study was to look at the

characteristics

and outcomes of patients who had DDC with osteosarcomatous differentiation managed within our unit. This paper shows that the side effects of chemotherapy were manageable and there is a sug- gestion of improved median survival. There is a significant risk of selection bias in this paper. Younger patients with better perfor- mance status will have been offered chemotherapy. These patients may have had less disease burden and so survived longer compared to the group not offered chemotherapy. However, this study would support a prospective registration study of chemotherapy out- comes in DDC to further explore this. Such a study should also consider qualitative patient outcomes examining the patients' per- 
ceptions of chemotherapy in the context of this disease to see why some patients decline chemotherapy.

This is the first retrospective analysis focused on the outcome of this subgroup of patients suffering from DDC with osteosarcoma- tous dedifferentiation. The presence of vascular invasion in the specimen was found to be an adverse prognostic factor, and this has not been reported previously in DDC with osteosarcomatous differentiation. This requires further investigation with a larger group of patients to confirm if this has value as a prognostic indicator.
This study demonstrates that cytotoxic chemotherapy can be given to appropriately selected patients without significant mor- bidity. It should continue to be considered in the management of patients with DDC with osteosarcomatous differentiation.

\section{References}

1 Dahlin DC, Beabout JW: Dedifferentiation of lowgrade chondrosarcomas. Cancer 1971;28:461-466.

2 McFarland GB, McKinley LM, Reed RJ: Dedifferentia- tion of low grade chondrosarcomas. Clin Orthop 1977;(122):157-164.

3 Campanacci M, Bertoni F, Capanna R: Dedifferentiated chondrosarcomas. Ital J Orthop Traumatol 1979; 5:331-341.

4 McCarthy EF, Dorfman HD: Chondrosarcoma of bone with dedifferentiation: a study of eighteen cases. Hum Pathol 1982;13:36-40.

5 Johnson S, Tětu B, Ayala AG, Chawla SP Chondrosar- coma with additional mesenchymal component (dedif- ferentiated chondrosarcoma): I. A clinicopathologic study of 26 cases. Cancer 1986;58:278-286

6 Frassica FJ, Unni KK, Beabout JW, Sim FH Dediffer- entiated chondrosarcoma. A report of the clinico- pathological features and treatment of seventy-eight cases. J Bone Joint Surg Am 1986;68:1197-1205
7 Capanna R, Bertoni F, Bettelli G, Picci P, Bacchini P, Present D, et al.: Dedifferentiated chondrosarcoma. J Bone Joint Surg Am 1988;70:60-69.

8 Mercuri M, Picci P, Campanacci L, Rulli E: Dedifferen- tiated chondrosarcoma. Skeletal Radiol 1995;24:409- 416.

9 Mitchell AD, Ayoub K, Mangham DC, Grimer RJ, Carter SR, Tillman RM: Experience in the treatment of dedifferentiated chondrosarcoma. J Bone Joint Surg Br 2000;82:55-61.

10 Dickey ID, Rose PS, Fuchs B, Wold LE, Okuno SH, Sim FH, et al.: Dedifferentiated chondrosarcoma: the role of chemotherapy with updated outcomes. J Bone Joint Surg Am 2004;86-A:2412-2418.

11 Bruns J, Fiedler W, Werner M, Delling G: Dedifferen- tiated chondrosarcoma - a fatal disease. J Cancer Res Clin Oncol 2005;131:333-339.

12 Staals EL, Bacchini P, Bertoni F: Dedifferentiated cen- tral chondrosarcoma. Cancer 2006;106:26822691
13 Staals EL, Bacchini P, Mercuri M, Bertoni F: Dediffer- entiated chondrosarcomas arising in preexisting osteo- chondromas. J Bone Joint Surg Am 2007;89:987-993.

14 Grimer RJ, Gosheger G, Taminiau A, Biau D, Matejovsky Z, Kollender Y, et al.: Dedifferentiated chondro- sarcoma: prognostic factors and outcome from a Euro- pean group. Eur J Cancer 2007;43:2060 2065.

15 Yokota K, Sakamoto A, Matsumoto Y, Matsuda S, Ha- rimaya $\mathrm{K}$, Oda Y, et al.: Clinical outcome for patients with dedifferentiated chondrosarcoma: a report of 9 cases at a single institute. J Orthop Surg 2012;7:38.

16 Italiano A, Mir O, Cioffi A, Palmerini E, PipernoNeu- mann S, Perrin C, et al.: Advanced chondrosarcomas: role of chemotherapy and survival Ann Oncol 2013; 24:2916-2922

17 Kawaguchi S, Sun T, Lin PP, Deavers M, Harun N, Lewis VO: Does ifosfamide therapy improve survival of patients with dedifferentiated chondrosarcoma? Clin Orthop 2014;472:983-989. 